\title{
O corpo da alma e seus estados: uma perspectiva amazônica sobre a natureza de ser-se humano' ${ }^{1}$
}

\author{
Anne-Christine Taylor
}

Dentre as várias "coisas que não precisam ser ditas" , está o fato do quão honrada me sinto pelo convite para ministrar esta conferência. Honrada, mas também, igualmente, se não em maior medida, horrorizada. Primeiramente, porque a ocasião evoca uma série de figuras paternas, mortas ou vivas, no confronto com as quais todos nós afiamos nossos instrumentos em nossa juventude e de cuja benevolência cabe, então, suspeitar; segundo, por eu ser uma antropóloga francesa, e às escaramuças - que são um dos grandes prazeres do longo relacionamento entre nossas duas comunidades científicas -, eu acredito que as apostas foram elevadas muito drasticamente. Terceiro, porque escolher um caminho em meio ao campo minado de paradigmas conflitantes em que consiste a antropologia hoje é uma questão inerentemente estressante.

$\mathrm{O}$ problema que quero considerar aqui, de importância central para Malinowski, é aquele da relação entre ambiente social e psicologia individual. $\mathrm{Na}$ verdade, esta conferência é uma espécie de resposta ao chamado feito no capítulo introdutório dos Argonautas para estudarmos "tudo aquilo que mais intimamente lhe diz respeito [ao homem], o domínio que a vida exerce sobre ele" (Malinowski, 1976, p. 38) ${ }^{3}$, na medida em que tento aqui definir o que implica, para um indivíduo, estar vivo e experimentar a individualidade [selfhood] de um corpo socialmente construído em uma cultura amazônica. Muitas pesquisas recentes se dedicaram a questóes deste tipo, de tal maneira que o corpo tem, em grande medida, substituído a sociedade como o principal foco analítico de nossa disciplina; na ver- dade, fomos ensinados, mais notadamente por Strathern (cf., por exemplo, 1992), que a sociedade não está em lugar algum senão no corpo, ou seja, na sequência dos conjuntos de relaçóes envolvidas em sua construção e desconstrução. Esta perspectiva lida efetivamente com as muitas dificuldades levantadas por reificaçōes sociológicas mais antigas, mas não é fácil reconciliá-la com qualquer visão plausível da individualidade, sendo difícil imaginar que as pessoas, na verdade, experimentam a si próprias simplesmente como uma sucessão de concatenaçóes estruturadas de fragmentos, e ainda mais difícil, na ausência de uma subjetividade minimamente estável, dar conta da continuidade relativa da tradição. Assim, considerando a importância desses trabalhos, meu objetivo é mostrar como uma imagem corporal é experienciada subjetivamente, e como uma pessoa é, desta forma, capaz de reproduzir as estruturas sociais que moldaram sua individualidade. Esta é, admito, uma questão absurdamente ampla, mas sua magnitude incita o tom provocativo que se ajusta, idealmente, ao formato de uma breve palestra. Como Nietzsche muito apropriadamente diz, grandes questóes são como banhos frios: deve-se entrar e sair deles o mais rápido possível.

Como ponto de partida, tomo um paradoxo menor implícito na etnografia das culturas indígenas das terras baixas da América do Sul. Por um lado, relatos antropológicos sobre esses grupos são repletos de afirmaçóes no sentido de que os índios amazônicos não acreditam que a morte possa resultar de causas naturais; ao contrário, eles a enxergam como causada pela ação humana 
maligna ${ }^{4}$. Sob tal perspectiva, a morte existe somente como uma forma de homicídio, evidente ou clandestino. Esta concepção de mortalidade é pensada como estando no cerne de dois tipos de práticas sociais altamente importantes, quais sejam, o xamanismo e as várias formas institucionalizadas de vingança e hostilidade - ora entre grupos domésticos, ora entre segmentos tribais e até mesmo entre tribos ou entidades étnicas. Por outro lado, em todos esses grupos, sempre nos deparamos com um ou vários mitos sobre a origem da mortalidade, nos quais a morte parece ser vista por um viés muito mais "naturalista": como uma característica do mundo tal como ele é e, em suma, como um inescapável fato da vida ${ }^{5}$. Este segundo ponto de vista parece implicar que os povos amazônicos, no fim das contas, concebem a morte como algum tipo de fenômeno natural universal. A 'racionalidade' óbvia desta crença, do nosso ponto de vista, atrai muitos antropólogos para um tipo familiar de funcionalismo espontâneo, que os leva a explicar a visão vingativa da mortalidade como um dispositivo ideológico necessário para a continuidade de instituiçóes sociológicas centrais, o pressuposto subjacente sendo o de que os índios não acreditam nessa visão vingativa da mesma maneira que acreditam na visão naturalista da morte. Afinal, se, de qualquer forma, as pessoas estão predestinadas a morrer, parece desnecessariamente redundante supor que estão sempre sendo assassinadas; assim, a abordagem homicida da mortalidade tende a ser tratada como se fosse meramente um astuto artifício sociológico.

Este tipo de abordagem é certamente inaceitável, como de fato qualquer antropólogo que pare para pensar sobre isto imediatamente reconhece, se não por outra razão, porque a "ideologia" é obviamente experienciada como verdade e não como falsa consciência. Além disso, com bases empíricas, os índios parecem adotar a visão homicida muito mais fortemente que a naturalística. Isto, entretanto, deixa-nos com o problema de dar conta da coexistência de dois conjuntos de crenças aparentemente contraditórias. É claro que se poderia argumentar, e atualmente se o faz com frequência, que a exigência de coerência lógica nas representaçóes específicas de uma sociedade dada náo seria mais do que preconceito antropológico, e que descriçóes que apresentam a cultura como um corpo auto-contido e logicamente impecável de proposições metafísicas não teriam absolutamente nenhuma semelhança com o modo como as pessoas realmente pensam ou agem. $\mathrm{Na}$ verdade, dada a ubiquüidade daqueles processos de "criolização" que muitos antropólogos enfatizam em seus estudos, assim como a compartimentalização dos processos mentais defendida pelos psicólogos cognitivistas, deveríamos considerar a possibilidade da contradição - e, de fato, esperá-la.

Permitam-me dizer desde já que, em termos gerais, endosso inteiramente as críticas "cognitivistas" das tradicionais visóes antropológicas de cultura, tais como aquelas desenvolvidas por Boyer (1990; 1993) ou Bloch (1991; 1992; 1993) em seus recentes trabalhos. É a mais pura verdade que nenhum povo pensa de fato da forma como os antropólogos parecem acreditar, e que as pessoas não recorrem a um modelo mental de sua cultura, como alguém faria a um texto, a fim de produzir afirmações e práticas não-contraditórias. Ao mesmo tempo, me oponho fortemente à visão de que não há sistematicidade durável na cultura além daquela produzida pelas narrativas antropológicas ou daquela criada localmente pelas dialéticas da etnicidade. $\mathrm{O}$ fato de que a cultura se assenta em grande medida naquilo que "não precisa ser dito", não quer dizer que qualquer coisa seja válida, e que não haja algum grau de integração entre modelos mentais compartimentalizados. Esta afirmação é puro senso comum. Ainda assim, não é fácil definir e nem dar conta da fonte e da natureza precisa 
desta relativa coerência ${ }^{6}$. Tenho a impressão que ela deva residir, em alguma medida, em uma certa propriedade de circularidade inerente aos modelos mentais compartilhados pelas pessoas de qualquer cultura; em outras palavras, no fato de que estes aglomerados conceituais auto-evidentes e discursivamente não elaborados, que podemos, por conveniência, chamar de premissas, devem se remeter uns aos outros, e é precisamente a partir deste processo circular de mútua referência que eles ganham sua qualidade de obviedade. No que se segue, tentarei mostrar o quanto uma definição única, precisa e intrincada de personitude e individualidade emerge justamente de tais cadeias de noçóes circulares e não elaboradas, e, ainda, buscarei entender como uma ideia complexa vem a ser desenvolvida sem que ninguém nunca efetivamente a pense ou expresse. E isto, é claro, levanta o problema do que as narrativas antropológicas podem e devem descrever, uma questão à qual retornarei mais tarde.

Os Achuar, povo jívaro das terras baixas do leste do Equador ${ }^{7}$, oferecem um perfeito exemplo da contradição implícita que mencionei acima. Em sua visão, doença e morte são, invariavelmente, o resultado de um ato inspirado por uma intencionalidade deliberadamente homicida, operacionalizada através do recurso ao maquinário invisível do enfeitiçamento causado por dardos invisíveis. Além disso, eles não fazem distinção precisa, nem mesmo lexicalmente, entre doença e morte, a diferença entre os dois estados sendo uma questão de grau, antes que de tipo. Isto implica que ambos são vistos como pontos em um mesmo processo, ligados por uma série de metamorfoses, e não como condiçóes ontologicamente distintas. Mais ainda, para eles a doença é um único fenômeno, sejam quais forem seus sintomas, físicos ou somáticos; não há doenças específicas, apenas sofrimento indiferenciado.

No entanto, como a maioria dos outros povos amazônicos, os Achuar também contam um mito caracteristicamente breve e conciso explicando a mortalidade como um resultado de um ato de desobediência acidental e inteiramente trivial ${ }^{8}$. Não tenho nenhuma intenção de me deter sobre este mito, que termina com a afirmação lapidar "que agora haja a mortalidade"; gostaria apenas de ressaltar dois de seus aspectos importantes. Primeiramente, este mito postula uma abrupta e massiva passagem de um tempo de indiferenciação, quando havia "somente vida", para um tempo em que havia vida e morte - ou seja, a vida como nós a conhecemos. Porém, o mito não diz nada sobre esta mudança brutal e não a descreve. Em outras palavras, ele focaliza um par de termos polares mais do que a natureza da relação entre esses termos. Segundo, conceitualizando a origem da finitude como resultado de um ato trivial de transgressão, o mito estabelece uma enorme - monstruosa, de fato - desproporção entre causa e efeito, entre um ato e sua consequência. Esta propriedade, comum a muitas narrativas míticas, poderia ser melhor explicada assumindo-se que certos tipos de mitos são na verdade proposições anti-causais: em outras palavras, eles não justificam o mundo e explicam como passou a existir ou como alguém deve se comportar, como se costumava pensar (Malinowski incluído); em lugar disso, eles descrevem o mundo tal como ele é de um modo altamente problemático, tornando, assim, paradoxal o óbvio. Este é precisamente o motivo pelo qual ninguém "acredita" no que dizem os mitos da mesma forma como se acredita, digamos, na descrição de um espírito. Se é assim, o que distingue as duas perspectivas sobre a mortalidade não é uma questão de conteúdo, mas de tipo de discurso: uma delas, a visão homicida, apresenta a morte como um processo gradual cujos extremos permanecem indefinidos, e sua ênfase está em explorar a natureza da relação processual entre polos não-marcados; a ou- 
tra - a visão mítica e naturalística -, apresenta termos nitidamente definidos em uma relação paradoxal e, portanto, indefinida. Assim, o que apareceu inicialmente como uma contradiçáo entre conteúdos, ou seja, entre duas concepçóes diferentes de morte, pode agora ser visto como uma articulaçáo provavelmente necessária entre dois tipos distintos de representaçãoo ${ }^{9}$ de uma relação.

Para entender a natureza desta articulaçáo, devemos começar olhando mais de perto a mortalidade como um modo processual de relação; e isto, por sua vez, implica em entender o que estar vivo significa em termos jívaro. Até certo ponto, isto é uma questáo simples: estar vivo é ser percebido, e se perceber, como uma pessoa, uma noção localmente abarcada pelo termo shuar. Esta expressáo se refere a um conjunto multi-folheado de relaçóes entre termos contrastivos: entáo, de acordo com o contexto, o termo shuar se refere a "minha parentela bilateral" em oposição a outras, "meu grupo local" em oposição a outros grupos territoriais, "Achuar" em oposição a outras unidades tribais jívaro, "Jívaro" em oposição aos brancos ou outros índios, e assim por diante. Em suma, o termo funciona como um classificador "nós/eles" genérico.

Para os nossos propósitos, o interessante sobre este classificador é que, em determinados contextos, o "nós" que ele define inclui duas classes de seres imaginários. Uma delas se refere a espíritos caracterizados pela sua aparência humana ordinária e seu comportamento inteiramente não -humano e, de fato, inumano: eles são solitários, cegos, não comem e existem em um estado de desejo generalizado e permanente. A outra classe inclui espíritos com aparência não-humana que, contudo, comportam-se como seres humanos, uma vez que usam língua e sinais, seguem regras morais e são dotados de emoçôes humanas. $\mathrm{Na}$ verdade, uma grande parte da mitologia jívaro é dedicada à descrição das açôes destas últimas criaturas; entidades ou shuar deste tipo também aparecem proeminentemente no discurso e na prática xamânicas, bem como nas magias de cultivo e de caça. Entretanto, se estes seres imaginários podem em certas circunstâncias ser definidos como pessoas, ou seja, como parte do "nós", em outros contextos eles são bem diferentes de pessoas reais, por várias razóes: às vezes porque estão mortos e outras vezes porque acredita-se que são como humanos apenas sob certas condiçóes de interação. O que eles de fato compartilham com os verdadeiros humanos vivos, no entanto, é a consciência e a intencionalidade. Essas são propriedades que para os Achuar não são limitadas a tipos específicos de seres, mas atribuíveis, em determinados contextos, a vários tipos diferentes de coisas, incluindo as inanimadas; a vida, em suma, é um estado mental postulado mais do que um estado da matéria.

Como consequência disso, ser um humano vivo e verdadeiro implica em exibir um tipo especial de aparência corporal, praticar certos tipos de comportamento comunicativo e social e possuir certos estados de consciência. Para especificar esta combinação que define a humanidade viva e verdadeira, devemos começar por olhar mais de perto a aparência corporal e explorar algumas noçóes achuar concernentes ao corpo. Os traços salientes do modelo mental que dão forma a estas ideias são os seguintes. Primeiro, e surpreendentemente, os Achuar possuem teorias notavelmente não elaboradas sobre a procriação, e têm, com efeito, muito pouco a dizer sobre a concepção e a formação de uma criança; questóes desta natureza são claramente tidas por eles como irrelevantes. Além disso, a gestação e o nascimento não são ritualizados e não há mitos explicitamente preocupados com a concepção e a procriação ${ }^{10}$. Segundo, se examinarmos as proibições e observâncias ligadas às substâncias e funçóes corporais - um conjunto de práticas geralmente considerado de 
O CORPO DA ALMA E SEUS ESTADOS: UMA PERSPECTIVA AMAZÔNICA SOBRE A NATUREZA DE SER-SE HUMANO $\mid 2$ I 7

particular importância para a compreensão das ideias indígenas sobre a formação do corpo e o modelamento da pessoa - algumas propriedades interessantes começam a emergir. As proibiçóes são mais numerosas e rigorosamente observadas precisamente naquelas práticas e situaçóes que, do ponto de vista indígena, envolvem um processo de transformação: fazer uma canoa, preparar o veneno curare, padecer por mordida de cobra. Assim, a relativa escassez e frouxidão das proibiçóes ligadas à gravidez e ao parto sustentam a visão de que estes processos não são vistos como semelhantes a outras metamorfoses culturalmente enfatizadas. Em outras palavras, e ao contrário da maneira como a morte é vista em certos contextos, o nascimento nunca é pensado como um processo de transformação, e não há, portanto, nenhum paralelismo entre o entrar no estado de ser um humano verdadeiro e vivo e o sair dele. Também deveríamos destacar que, em relação aos seus efeitos, as substâncias corporais não formam uma classe distinta de outras substâncias, não corporais: o sêmen, por exemplo, tem as mesmas propriedades que o curare, que o veneno de cobra, ou que a sensação de queimação de pimenta vermelha; e o sangue menstrual é apenas sangue, ou, se ele tem qualquer poder, este é proveniente de atributos não específicos, tais como a potência do vermelho ou a de ser pesado. Finalmente, coisas tidas como vivas, ou seja, às quais se atribui intencionalidade e consciência, são todas fundamentalmente similares em termos de atributos orgânicos e mecanismos fisiológicos: um morcego ou um cachorro, ou mesmo um pé de mandioca, são todos vistos como organizados da mesma forma. Eles funcionam de acordo com processos biológicos idênticos, e sua matéria corporal aparências à parte - é a mesma. Se nós humanos não estamos normalmente cientes deste fato, isto se deve a razôes epistemológicas - porque nós normalmente não nos comunicamos com eles - e não porque esses metabolismos são ontologicamente distintos.

Somos assim levados à conclusão de que o que diferencia as espécies é essencialmente a forma ou, mais precisamente, a aparência. Como já mostrei em outra ocasiáo (Taylor 1993), do ponto de vista jívaro, esta aparência se refere ao conjunto de formas corporais diferenciadas - particularmente rostos -, específicas a cada classe de seres animados. Estas formas existem em número limitado e são infinitamente recicladas, o que explica porque não existe aqui criação natural e porque $o$ nascimento não é visto como um processo de transformação ou de "fabricação" que adiciona alguma coisa nova ao mundo. $\mathrm{O}$ nascimento é um reaparecimento, e a pessoa achuar, deste modo, chega pronta em termos de atributos corporais. Segue-se disso que a noção Jívaro de identidade pessoal deve ser enraizada na percepção de singularidade da forma, e não, como as noções ocidentais pós-freudianas nos fariam acreditar, em uma realização gradual da integridade e autonomia corporais, uma vez que os corpos jívaro não possuem especificidade orgânica. Ainda assim, assumir que os Achuar, na verdade, experienciam a si próprios como singularidades puramente genéricas desafia o bom senso. Uma forma impessoal particularizada pode dar ao Eu [self] sua integridade, mas obviamente náo pode lhe conferir subjetividade.

A subjetividade, entretanto, é primariamente uma questão de refração: ela se origina na noção que alguém tem da percepção que outros têm de seu próprio Eu. E é ai que devemos procurar por uma solução para o enigma que acabei de evocar - de como a experiência de um corpo impessoal, externamente criado, pode ser vivenciada subjetivamente. Acredito que tal solução possa ser encontrada na teia de noções referentes ao afeto e à memória, se por memória entendemos a imagem mental que 
formamos de pessoas ou coisas. Como todos nós sabemos a partir da leitura do belo livro de Gow (1991), a memória, para os povos amazônicos, está intimamente ligada ao parentesco. De certa forma, na verdade, ela é o próprio parentesco. Nessa visão, relaçóes sociais consistem na condensação e na memória dos estados afetivos construídos pelas interações diárias nos atos de alimentar, partilhar e trabalhar. A imagem mental pessoal que se tem dos outros como parentes é moldada por esta teia de sentimentos; assim, a imagem do Eu, na medida em que se baseia na atribuição de imagens que outros têm dele, é necessariamente permeada pela memória que os outros possuem de você. Ela é precisamente uma representação desta imagem genericamente singular, embora individualizada, da pessoa, denotada pela expressão vernacular wakan, um termo normalmente traduzido como "alma" e que, na verdade, refere-se à imagem refletida de uma coisa, à aparição de alguém em um sonho, como também à consciência daquele que sonha. Sobretudo, refere-se ao fantasma de uma pessoa falecida recentemente, ou seja, a uma memória mutilada, na medida em que consiste na substantivização $\mathrm{da}$ intersubjetividade outrora fundida com a imagem de uma forma corporal que não existe mais. A relação constitutiva entre subjetividade e laços interpessoais nos permite entender porque a visão, a linguagem e, de uma maneira mais geral, a comunicação constituem um eixo tâo vital na definição da individualidade, uma vez que a imagem refratada é, em grande medida, uma descrição implícita, e até às vezes explícita, da pessoa. Os próprios Achuar estão bem conscientes desse fato, como pode ser deduzido, dentre outras evidências, da estrutura de seus cantos mágicos de amor. Esses são, invariavelmente, descrições verbais, endereçadas à pessoa amada, do estado que ele ou ela está experimentando ao ver, ou melhor, ao sentir, uma imagem magicamente induzida do emissor ${ }^{11}$. Em suma, os Achuar certamente endossariam a afirmação de Wittgenstein de que o corpo é a melhor imagem que podemos ter da alma, particularmente por sua reversibilidade, uma vez que é igualmente óbvio para eles que a alma também é a melhor imagem que podemos ter do corpo como uma forma personalizada genérica.

A socialidade, como uma memória inerentemente afetiva, foi descrita com grande sutileza e perspicácia pelo que, em Paris, chamamos de escola inglesa de americanismo. Contudo, as descrições de nossos colegas me parecem, com frequência, um tanto unilaterais e, de fato, surpreendentemente angelicais, uma vez que tendem a minimizar um componente vital das relaçóes sociais, quais sejam, a hostilidade ou a disposição vingativa. Enquanto os ingleses são muito bons no que toca ao amor, acredito que nós franceses levamos vantagem na questão do ódio ${ }^{12}$. A hostilidade é um aspecto particularmente importante das relaçóes sociais e das configuraçóes psicológicas a elas inerentes, sobretudo em uma sociedade como a dos Jívaro, que é estruturada por vendetas endêmicas e guerras intertribais. Aprender a odiar, ou antes, absorver o ódio do tecido do ambiente social, é tâo importante para eles quanto aprender a amar. E é claro, a hostilidade também alimenta a experiência do Eu; ela colore, tanto quanto o amor, a textura da imagem corporal como aparência singularizada que, como vimos, está no cerne da individualidade jívaro.

Se o "Eu" enquanto pessoa é um estado, ele é também, por natureza, um estado altamente instável, na medida em que a paisagem interior da pessoa é moldada pelo entendimento que ela tem da percepção que os outros têm dela mesma. A integridade da sensação que se tem de si mesmo é vulnerável em dois aspectos. Primeiramente, ela está exposta à morte de outros, ao estilhaçamento daquele espelho do qual depende - uma ocorrência muito frequente na vida 


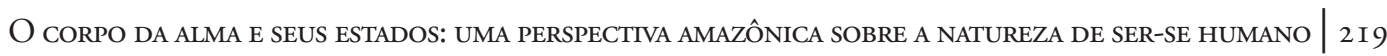

de um Achuar e que provoca, como primeira reação, uma raiva intensa e socialmente direcionada. Segundo, ela está exposta à instabilidade crônica das relaçóes em uma sociedade baseada em uma frouxa trama de parentelas, cujas fronteiras variam constantemente no fluxo de vendetas endêmicas e de alianças cambiantes. A vida tradicional entre os Jívaro gera, então, um tipo de paranoia latente, racional, uma vez que membros da família próxima podem tornar-se suspeitos de traição em períodos de conflito aberto. A suspeita cai primeiramente sobre os afins, é claro, mas pode incluir até mesmo consanguíneos do mesmo sexo, como irmãos ou filhos ${ }^{13}$. Esta incerteza constante sobre a real natureza dos sentimentos que os outros nutrem por alguém não pode deixar de ter consequências para a textura e os fundamentos da individualidade $^{14}$. Eu diria que é aí que a doença entra. A doença, nos termos jívaro, é o sofrimento experienciado pelos indivíduos quando se veem sobrepujados pela ambiguidade do ambiente social e então perdem um sentido nítido de sua identidade; ou seja, quando sua percepçấo do Eu é obscurecida pela incerteza. $\mathrm{Na}$ verdade, eu conjeturaria que é o alto nível de ansiedade gerado pela extrema imprevisibilidade das relaçóes sociais inerentes à existência jívaro que explica porque qualquer aflição, não importando sua origem e seu caráter aparentemente benigno, transforma-se em sintoma de feitiçaria se perdura por mais de poucos dias ou até mesmo horas, e porque a taxonomia relativamente detalhada de patologias que os informantes Achuar desenvolvem em abstrato se reduz tão rapidamente a um único e massivo contraste entre a "saúde" e o sofrimento indiferenciado - o que vale dizer, ao morrer ${ }^{15}$.

É esta quebra de clareza na percepção do Eu, experienciado como sofrimento e conceitualizado como uma investida homicida intangível, que justifica recorrer à prática terapêutica xamânica.
Como Severi (1993) demonstrou para a cura kuna da loucura, a terapia xamânica é uma forma de cura baseada na construção de uma estrutura pragmática complexa na qual o xamá produz uma descrição, geralmente incompreensível ao paciente, de sua interação comunicativa com espíritos estrangeiros. $\mathrm{O}$ xamã, desse modo, cria um análogo do estado de confusão do paciente, com a diferença crucial de que ele, o xamá, domina este mundo caótico através da visão e da palavra e se comunica com seus habitantes por intermédio de seus espíritos familiares, enquanto o paciente, por sua vez, está preso a um estado de colapso comunicativo consigo mesmo e com os outros. É através dessa transmutaçâo da desordem interna e muda em uma clara, estruturada e explícita, embora incompreensível, alteridade que as pessoas são afinal restauradas a um estado normal de autoconsciência; ou seja, um estado no qual o Eu e o mundo podem coexistir em níveis aceitáveis de ambiguidade.

Os Jívaro, entretanto, possuem uma outra maneira de lidar com a fragilidade da individualidade. Eles recorrem a uma experiência ritual que é, em muitos sentidos, uma imagem espelhada da cura xamânica. Eu me refiro aqui à busca pelas assim chamadas visóes arutam, nas quais a pessoa pode, no curso de um ritual privado envolvendo isolamento, jejum rigoroso e a ingestão de grandes doses de drogas alucinógenas, receber uma mensagem ou visão relativa a seu futuro. O espírito responsável por essa profecia, o arutam ou "coisa antiga", assume a forma de um Jívaro morto que, depois de uma complicada e amedrontadora série de metamorfoses, aparece brevemente em pessoa para aquele ou aquela que o busca e lhe dirige a palavra. No caso dos homens, essa mensagem geralmente se refere ao resultado de um ato de guerra ou de um assassinato por vingança, o qual, é claro, eles se sentem então compelidos a concretizar. A experiência arutam está, assim, diretamente ligada 
àquelas situaçóes e relaçóes interpessoais mais densamente carregadas de imprevisibilidade e se baseia na mesma lógica que subjaz ao recurso à cura xamânica. Desnecessário acrescentar que a estrutura pragmática da interação entre aquele que busca o espírito e este último é tão complexa quanto aquela implicada na cura xamânica - em certo sentido, com efeito, até mais complexa. (Refiro-me aqui à maneira pela qual as circunstâncias estereotipadas envolvendo o encontro ritual são constitutivas do significado do evento). Irei, portanto, me limitar a sublinhar duas características proeminentes da busca pelo arutam.

Primeiro, ela se centra no enquadramento ritual das interaçóes ordinárias sobre as quais a subjetividade, tal como percebida pelos Jívaro, se constrói. Assim, quando os Achuar falam da mensagem arutam como uma espécie de 'alma' que a partir de então se tornará uma parte deles, estão evocando uma reificação, projetada no futuro, de uma imagem do Eu enraizada em um tipo especial de relação intersubjetiva, aquela entre eles próprios - mais precisamente, um estado modificado de sua consciência - e o arutam. Essa hipóstase tem como modelo a introjeção de uma imagem atribuída do Eu que subjaz aos estados normais de subjetividade. Portanto, assim como o wakan - a alma do corpo - sobrevive brevemente ao recém-falecido como uma substantivizaçáo da memória que os parentes vivos guardam dele, também a visão arutam que ele ou ela recebeu encapsula a descrição, ou imagem, que o espírito faz de seus futuros Eus. $\mathrm{O}$ wakan, em suma, é uma reificação de uma memória atribuída, enquanto a 'alma' arutam é uma reificação da individualidade projetada. Paradoxalmente, isso é, de fato, tudo o que em última instância resta das pessoas, sob a forma da 'coisa antiga' ou arutam que elas um dia se tornarão. Em outras palavras, o ritual arutam não está ligado a uma elaborada teoria cosmológica ou ontológica. Ele é baseado na mesma percepção da subjetividade e da intersubjetividade que informa a noção de wakan, e seus significados específicos estão enraizados na construção ritual de um contexto particular de interação, mais do que em uma elaboração de conteúdo. Em segundo lugar, o efeito ou resultado da busca pelo arutam brota de um evento de hipercomunicação, de uma espécie de saturação de certeza e de significado não-ambíguo. Contudo, esse vislumbre de um destino livre de qualquer imprevisibilidade deve permanecer indescritível, na medida em que é estritamente proibido falar sobre a mensagem recebida do arutam. Se alguém fizesse isso, imediatamente perderia o benefício da visão ou, na verdade, a própria visão ou mensagem como um tipo de substância anímica [soul-stuff] por meio da qual o senso do Eu é fortalecido. E isso, afinal, é a motivação primária para se submeter à experiência mística, bem como seu resultado final: a aquisição de invulnerabilidade, manifestada pela contundência do discurso e da atitude, por uma pintura facial de um certo tipo e por uma raiva aguçada - ou seja, por um impulso homicida intensificado ${ }^{16}$. Em suma, assim como a doença leva a uma perda da capacidade de se comunicar a não ser pela linguagem muda dos sintomas, o estado de ultra bem-estar proporcionado pelo encontro com um arutam implica a suspensão da troca linguística e a manifestação de um leque de signos indiretos ou 'sintomas' expressando uma condição de individualidade amplificada.

Portanto, se compararmos os dois tipos de experiência ritual brevemente evocadas aqui, a cura xamânica e a busca pelo arutam, temos, de um lado, uma descrição mediada de um caos controlado por meio da qual um indivíduo pode se livrar do sofrimento ocasionado por uma esmagadora ambiguidade e pela erosão da individualidade que ela implica e, de outro, uma visão ou "audição" secreta, também mediada, marcada por uma certeza absoluta, que dramaticamente intensifica a força da individualidade. Eu falo 
deliberadamente de mediação no caso da busca pelo arutam porque, embora aquele que busca o espírito esteja só durante o ritual, não é ele próprio quem recebe a mensagem da aparição, mas sim seu wakan, a alma de seu corpo, sendo todo o sentido das drogas e do jejum o de induzir um estado de consciência dissociada. Então, de fato, a estrutura que subjaz à situação de comunicação em ambos os casos é similar. Na sessão de cura, o paciente está 'como morto', inteiramente passivo, enquanto o xamã gradualmente identifica a si próprio com os componentes de desordem, figurados como criaturas e línguas estrangeiras, e assim os ordena enquanto os descreve. No ritual arutam, aquele que busca o espírito também está figurativamente morto (durante seu período de isolamento, seus parentes devem evitar evocar sua imagem, do mesmo modo como evitariam pensar sobre uma pessoa recentemente falecida), de modo que sua 'alma', sua consciência desintencionalizada, pode gradativamente se tornar parecida com a pessoa verdadeiramente morta que, por fim, aparecerá para ele; e essa interação com uma entidade que está estruturalmente tão 'fora' da sociedade quanto os estrangeiros encontrados pelo xamã gera uma clareza absoluta, não apenas como cura - o que é realmente um retorno ao $\mathrm{Eu}$ - mas, sobretudo, como uma amplificação do Eu ou de um estado de super -individualidade.

Permitam-me resumir essa breve descrição das noçóes jívaro sobre a pessoa e a experiência do Eu que elas implicam. Comecei mostrando que a pessoa é definida negativamente, em baixo -relevo, por assim dizer, pela intersecção de um certo número de pressupostos inexplícitos acerca da animação (vista como subjetividade imputada), da socialidade (vista como comunicação ordenada e, portanto, implícita nas noçôes indígenas de animação) e, finalmente, da forma, superfície ordenada, aquele princípio de especiação que divide um modelo ou matéria fisiológica de outro modo generalizados. Prossegui mostrando que a superfície apropriada para os humanos enquanto uma classe de seres - ou seja, sua aparência - é concebida como retirada de um estoque finito de formas distintivas e recicláveis. Assim, o senso do Eu jívaro é baseado na fusão de uma imagem corporal singular, porém, genérica e da percepção emocionalmente carregada que outras pessoas têm dessa imagem corporal, por meio da qual ela vem a ser experienciada como unicamente pessoal. Argumentei, então, que porque a individualidade é texturizada pela intersubjetividade, porque a intersubjetividade é ela própria criada no contexto de relaçóes sociais, e porque as relações sociais entre os Jívaro envolvem laços de parentesco instáveis e formas institucionalizadas de violência recíproca - porque, em suma, eles vivem em um mundo permeado de incerteza e hostilidade -, o senso achuar do Eu é altamente vulnerável. Ele oscila entre estados de incerteza, erosão e colapso, de um lado, experienciados como um sofrimento indiferenciado, homicida, que requer tratamento xamânico e, de outro, estados de amplificação provocados por uma experiência mística de certeza.

Isso me leva ao cerne do meu argumento. Em termos analíticos, uma pessoa ou um Eu não é uma coisa, uma essência específica moldada por uma teoria explícita ou implícita, ou, em outras palavras, um conceito indígena. Ser uma pessoa humana viva não é um estado definido enquanto tal - não há nenhum discurso canônico sobre 'a pessoa', e ninguém jamais dirá 'essa é a nossa ideia do que um homem ou uma mulher é -, mesmo que esse estado seja circunscrito de maneira precisa pela articulação de um conjunto de premissas não explícitas. Ser uma pessoa é, portanto, um leque ou um gradiente de configuraçôes relacionais, um conjunto de nexos em uma cadeia de metamorfoses simultaneamente aberta e delimitada. A cadeia é aberta porque a própria morte é um processo sem fim, como é a 
passagem do 'nós' para o 'eles', de Jívaro a estrangeiro; é delimitada, entretanto, porque ser um Eu vivo só pode ser definido por contraste seja a um estado de ser menos do que vivo, na doença, seja a um estado de ser mais do que vivo, por meio da aquisição de um arutam. E esse é o motivo pelo qual tanto encontramos as oposiçóes rígidas e problemáticas estabelecidas nas narrativas míticas - vida versus morte - quanto, no ritual e em outros campos da prática, encontramos vida e morte como um processo contínuo. Essa é a chave para o paradoxo com o qual comecei esta palestra, que diz respeito à existência de duas noçóes aparentemente contraditórias de morte. Não se trata, com efeito, de duas concepções diferentes e compartimentalizadas da mortalidade, uma naturalística e outra persecutória, mas antes de duas perspectivas mutuamente implicadas, uma focando nos termos em lugar da relação entre eles, a outra focando na relação e colocando os termos entre parênteses. Além disso, a atualização das diferentes ocasiōes em que a noção do Eu é evocada forma uma cadeia: a busca pelo arutam leva ao homicídio, agressão e suspeição, que são a causa da doença e da desorientação, que, por sua vez, exigem ou tratamento xamânico ou outras buscas pelo arutam, e assim por diante. Isso significa que os diferentes tipos de relaçóes e de autocriações discutidas aqui estão relacionadas não apenas estruturalmente, mas também praticamente.

A abordagem da questão da personitude delineada acima tem algumas implicaçóes mais amplas, sobre as quais, à guisa de conclusão, eu gostaria de chamar atenção. A maior parte dos estudiosos dos Jívaro, eu própria incluída, tende a considerar o complexo do arutam - porque é intelectualmente espetacular e também devido a seus aspectos esotéricos -, como o próprio coração da cultura jívaro, a base mesma de sua identidade, tanto para os índios quanto para seus etnógrafos. Ainda assim, se é verdade que até recentemente a grande maioria dos homens achuar havia experienciado encontros arutam, é igualmente verdade que essas buscas místicas dizem respeito apenas a um estado extremo da personitude jívaro, e não à 'Jivaronidade' enquanto tal, e a maioria dos informantes diria que se poderia viver uma vida jívaro ordinária e ser um Jívaro (ainda que reconhecidamente de segunda classe) sem nunca experienciar um encontro arutam. Assim, ao afirmar que o complexo arutam se situa no coração da cultura jívaro, antes que em sues contornos, criamos uma imagem equivocada não apenas do próprio complexo arutam como da cultura jívaro em geral. Tampouco essa distorção ótica é uma particularidade dos estudos jívaro. Suspeito que muitas de nossas descriçôes etnográficas estejam de fato baseadas em uma mistura similar entre 'cultura' e 'estados extremos'. Por exemplo, qualquer descrição que pretenda caracterizar a cultura simbólica desta ou daquela sociedade por meio da generalização de conceitos deduzidos de qualquer tipo de discurso especializado só pode estar errada: errada porque é cega à importância da prática e da contextualização, porque assume a cultura como um sistema de linguagem e pensamento compartilhados (reservadas diferenças de sexo e a geração) por todos. Premissas semânticas podem, com efeito, ser compartilhadas por todos, mas a pragmática muito provavelmente não o é: na medida em que as condiçóes de uso determinam como essas premissas são elaboradas, expressas e experienciadas, a afirmação de que uma dada representação é comum "à sociedade" é com certeza insustentável se seu significado está enraizado em situações de interação e em formas de contextualização que não são de modo algum coletivas.

Meu segundo ponto é, em certo sentido, uma consequência do primeiro. Se minha descrição da pessoa e da individualidade achuar como um repertório de diferentes estados de ser tem uma 
validade mais do que local, então será necessário rever nossa abordagem do problema da aculturação. Será necessário, em particular, não mais pensar a aculturação como uma erosão gradual e a consequente reformulação das crenças centrais de uma cultura. Entre os Achuar, a aculturação sempre esteve presente, situada no próprio cerne ou 'meio-termo' do sistema cultural: não se trata tanto de uma questáo de perda, mas da sensação de não se ser mais compelido a definir o Eu pela experienciação de toda a gama de estados que ele normalmente implica. A aculturação começa em uma condição de aprisionamento em um estado de normalidade indefinida ou não marcada, devido ao não mais engajar-se nas situaçôes de interação características dos estados extremos; portanto, um Jívaro aculturado, ou potencialmente aculturado, é simplesmente um ser ordinário, aquilo os próprios Achuar, muito apropriadamente, chamam de nangami shuar, uma "pessoa apenas" [just-so person], o tipo de indivíduo que tem a capacidade de entrar e sair da sua ou de outras culturas com facilidade, desde que ele permaneça em seus meios-termos ou 'estados zero'.

Em nenhum momento afirmei estar apresentando uma teoria indígena, ou mesmo explicitando um conjunto de representaçóes coletivas implícitas ou inconscientes sobre a pessoa, a vida ou a morte; simplesmente segui algumas das conexôes entre aglomerados de "coisas que não precisam ser ditas”. Creio, no entanto, que mesmo essa minha apresentação superficial dessa cadeia de relaçóes tenha sido suficiente para evocar a singularidade estilística da cultura jívaro. Tomados separadamente, vários elementos dos esquemas conceituais sobre os quais ela se funda podem ser encontrados disseminados por toda a Amazônia; da mesma maneira, os mecanismos cognitivos e, mais especificamente, as estruturas lógicas subjacentes à pragmática da cultura achuar também podem ser encontrados por toda a Amazônia e, na verdade, muito mais além. A particularidade da cultura achuar deve, portanto, enraizar-se no estabelecimento de um certo tipo de circularidade lógica entre esses fragmentos cognitivos e nocionais. Essa é uma visão de senso comum e, portanto, uma conclusão bastante capenga, mas nem por isso precisa ser uma conclusão derrotista. Ela nos permite, em particular, contornar aquela situação, semelhante ao princípio da incerteza dos físicos, em que se nos concentramos em mecanismos cognitivos, deixamos a cultura escapar, e se descrevemos a cultura da maneira tradicional, contrariamos aquilo que a pesquisa cognitiva nos ensinou sobre o funcionamento da mente. Mecanismos cognitivos como tais não constituem nossa província enquanto antropólogos, primeiramente porque, em última instância, eles provavelmente são invariantes e, em segundo lugar, porque é praticamente impossível reproduzir os protocolos experimentais agora em uso na psicologia cognitiva em situaçôes normais de campo. Mas tampouco é a cultura aquilo que costumávamos considerá-la. Obviamente não podemos continuar dizendo “os Achuar pensam que...”, porque o conteúdo do pensamento que geralmente nos propomos a descrever não é, de fato, o que eles realmente pensam. E, ainda assim, nós devemos, em certo sentido, continuar dizendo exatamente isso - esta é realmente a boa notícia. Pois, se nosso objetivo é adquirir (e compartilhar com nossos leitores) uma compreensão dos pensamentos e experiências de povos cujos pressupostos e estilos de vida são diferentes dos nossos, só podemos fazê-lo, é claro, enunciando e explicitando a grande parcela da cultura que "não precisa ser dita", que escapa às conceitualizaçóes indígenas porque está incorporada e é adquirida na prática, antes que pelo discurso. Certamente, a versão da cultura que somos, assim, levados a produzir, em nenhum sentido espelha o universo mental de nossos informantes. Porém, não vejo como poderíamos 
sequer imaginar esse universo sem que inventássemos para nós mesmos e para nossos leitores um tipo de "substituto" discursivo para uma cultura na qual não fomos socializados, dando-nos desse modo os meios de atingir algum grau de empatia com a vida e os pensamentos do povo que estamos estudando. Devemos, em outras palavras, tratar a rede de pressupostos frequentemente inexplícitos e não elaborados que é constitutiva da cultura como se ela fosse uma metafísica, porque essa construçáo ficcional é necessariamente nosso procedimento essencial - com efeito, nosso único procedimento - para trazer à luz e para verificar a circularidade necessária da combinação de premissas encontrada em qualquer cultura, assim como o único meio que nos permite o exercício daquela "introspecção analógica" que está no cerne de nossa disciplina. E isso significa que podemos prosseguir alegremente trabalhando em nossas monografias sócio-cosmológicas, desde que respeitemos dois conjuntos de condiçôes. Primeiro, temos que prestar muito mais atenção do que antes aos aspectos contextuais do discurso e da comunicação, deixar de supor que a cultura é um texto coletivo e ser mais realistas em nossa descrição de quem pensa o que e como em cada circunstância. Segundo, devemos aceitar que nossas descrições etnográficas são complexos experimentos mentais antes que versóes precisas dos sistemas indígenas de pensamento, e vê-las como ferramentas conceituais inerentes à prática e à escrita da antropologia. Pode ser que essa ferramenta seja incômoda; porém, se levarmos em consideração a complexidade do fenômeno com que, de comum acordo, supóe-se que a antropologia trabalha, precisamos reconhecer em nossas monografias instrumentos bastante econômicos (em todos os sentidos do termo), e a desproporção entre nossos meios - uma complexa ficção controlada que não almeja uma descrição realística de fenômenos mentais - e nossos fins - a descoberta e a verificação da natureza das cone- xôes entre modelos mentais - não é tão grande quanto pode parecer à primeira vista.

A mudança de perspectiva que sugeri não é uma pretensão absurda e não implica nenhuma revisão importante de objetivo ou de método. Entretanto, ela parece oferecer à antropologia algum tipo de futuro enquanto empreendimento intelectual válido, o que, certamente, é mais do que pode ser dito seja do objetivismo brando que praticamos por tanto tempo, seja do veículo autodestrutivo projetado pelos militantes mais zelosos do pós-modernismo. Além do mais, deslocamentos menores de ponto de vista do tipo que estou advogando são bastante típicos da tradição intelectual de nossa disciplina; com efeito, a ocorrência dessas mudanças sutis, que frequentemente passam despercebidas, é precisamente o que faz a antropologia aparecer para os leigos como uma reexposição sem fim dos mesmos problemas, ao passo que seus praticantes sentem que ela está em um progresso constante. Assim, gostaria de pensar que a banalidade da minha conclusão é uma espécie de prova de que a abordagem que estou defendendo não é totalmente alheia ao grande cânone tão notavelmente modelado e ilustrado pelo cientista cuja memória honramos hoje.

\section{Notas}

1. Esta fala foi originalmente apresentada na "Conferência em homenagem à Malinowski” [Malinowski Memorial Lecture], em 1993 e publicada sob a forma de artigo no periódico Journal of the Royal Anthropological Institute (vol. 2, n. 2, 1996, pp. 201-215).

2. A expressão se refere a um artigo de $\mathrm{M}$. Bloch publicado em Kuper 1992 com o título "What goes without saying. The conceptualization of Zafimaniry society”. [N.T.: A expressão what goes without saying, ou things that go without saying refere-se a algo dotado de um caráter auto-evidente, que dispensa explicitação, ou seja, "coisas que não precisam ser ditas".] Ao longo desta palestra, irei frequentemente me referir às hipóteses apresentadas nesse texto. Gostaria de agradecer à Bloch por seus comentários 
iluminadores sobre um rascunho anterior deste trabalho e pela sua ajuda no preparo do mesmo para a publicação.

3. N.T.: Tradução extraída da versão brasileira do livro.

4. Essa é uma simplificação brutal. Seria mais preciso dizer que a agência intencionalmente maligna que causa a morte é geralmente antropomorfizada, mas não necessariamente humana. Para exemplificaçốes da visão que supôe uma agência estritamente humana ver, por exemplo, Capistrano de Abreu (1941: 140-1) sobre os Kashinaua e Harner (1972: 152-3) e Descola (1994: 257-70) sobre os Jívaro Shuar e Achuar. Entre os Piaroa, o agente pode ser uma divindade, um animal ou um feiticeiro estrangeiro (Overing, 1985); entre os Yagua, ele pode ser humano ou vegetal (Chaumeil, 1983: 264-311); entre os Guajiro (Perrin, 1992: 209-12) e os Tukano (Reichel-Dolmatoff, 1971: 80-6) ele pode ser um animal (enquanto animal ou sob a forma de Mestre de animais).

5. Uma amostra desses mitos é analisada por Lévi-Strauss (1967).

6. Dois pontos estão em questão aqui. O primeiro é o problema da integraçáo de modelos mentais. Entre os antropólogos, a discussão sobre este ponto se centrou, na medida em que existiu, na maneira pela qual a cognição de domínio específico [domain-specific cognition] poderia, por meio da capacidade de meta-representação, ser culturalmente elaborada (Atran, 1993 [seguindo Sperber, 1990]; Bloch, 1993; Sperber, 1993). Como aponta Bloch, esse tema, que obviamente é de interesse vital para os antropólogos, ainda foi muito pouco explorado. O segundo ponto é a questão da unidade de uma dada cultura. Antropólogos 'cognitivistas' que, em nome do realismo psicológico, se recusam a considerar a cultura como a manifestação de um script compartilhado subjacente ou, a fortiori, como expressão de estruturas inconscientes, têm muita dificuldade de dar conta desse aspecto de seu objeto de pesquisa. Eles tendem a contornar o problema argumentando que a coerência e a sistematicidade sáo simplesmente um produto da etnografia, ou ainda, que a própria noção de cultura é desprovida de significado. A cultura pode bem não ser muito mais que "uma orquestra de segunda classe tocando uma melodia lembrada pela metade", sem a ajuda de um condutor (Lawson, 1993: 206), mas ainda nos resta explicar como e porque todos se lembram da mesma melodia, ainda que imprecisamente, e porque o nível de cacofonia em qualquer "cultura" dada é, com efeito, surpreendentemente baixo.

7. Esta conferência se baseia em dados coletados por P. Descola e por mim mesma durante 26 meses de tra- balho de campo entre 1976 e 1979, em 1984 e em 1992. Ela também se ancora, é claro, na extensa literatura sobre os Jívaro, particularmente nos trabalhos de Brown (1985), Harner (1972), Karsten (1935) e Pellizzarro (1978; 1980).

8. Para algumas versóes publicadas desse mito como ele é contado pelos Schuar do Equador, ver Pellizzarro (1980).

9. Implícita nessa formulação está a ideia de que a diferença entre os discursos mítico e ritual é inerente a seus respectivos significados; i.e., parte do sentido de uma narrativa mítica é derivado do fato de que ela é implicitamente contrastada com um pronunciamento ritual e vice-versa. Embora seja perfeitamente legítimo isolar tais corpos de discurso para propósitos analíticos, em algum ponto, suas interconexôes, mesmo que pareçam inteiramente negativas, devem ser levadas em consideraçáo.

10. Com a exceçáo de um corpo de mitos relativos à mudança da cesariana letal para o parto "natural". Esses mitos são comuns ao menos entre os Shuar, Achuar e Aguaruna. De acordo com essas narrativas, o nascimento de uma criança costumava in illo tempore implicar a morte da máe, uma vez que era necessário cortar a barriga das gestantes para que os bebês pudessem nascer. Os ratos se compadeceram das mulheres e fizeram um acordo com elas, ensinando-as o parto natural em troca de uma parcela de suas colheitas de amendoim, para algumas versóes shuar deste mito, ver Pellizzarro (Ib., Idem).

11. Esses cantos pertencem a uma classe de enunciaçóes chamadas anent, um tipo de discurso anímico [soul-speech] que transcende canais normais de comunicação. Aqui segue um breve exemplo de uma dessas invocaçôes, silentemente dirigida por uma mulher a seu marido ausente:

Go flock to my little father's heart/ make him return to me crying pitifully/ go flock to his thoughts (and make him cry) "why does this feeling came to me?"/ fly to his thoughts and make him awaken in tears/ (saying) "why do I awaken thus?/ Oh, she's angry at me/ she is going to leave me!"/ make him awaken with this thought/ crying, crying, go flock to him/ my little wakan, go flock to him (tradução minha; a versão vernacular, juntamente com dados linguísticos, pode ser lida em Taylor \& Chau, 1983: 118 119). [Se junte ao coração do meu pequeno pai / faça-o voltar para mim chorando lastimosamente / Vá se juntar aos seus pensamentos (e faça-o chorar) 'porque estou me sentido assim?' / Voe até seus pensamentos e faça-o acordar chorando / (dizendo) 'por que eu acordo, então? / Oh, ela está com raiva de mim / ela vai me deixar!' / faça-o acordar pensando 
isso / chorando, chorando, se junte a ele / meu pequeno wakan, se junte a ele.]

12. A perspectiva irênica de alguns americanistas britânicos está ligada à sua ênfase na moralidade, i.e., nos valores normativos da socialidade, tal como expressa por seus informantes e incorporada em suas práticas; ver, por exemplo, Belaunde, 1992; Gow, 1991; McCallum, 1989; Santos-Granero, 1991. Por outro lado, os americanistas franceses, que geralmente aderem a uma abordagem estrutural-durkheimniana, tentam construir um modelo das relaçóes sociais observadas enfatizando o aspecto "construtivo" (no sentido sociológico) do conflito. Para exemplos disso, ver Albert, 1985; Clastres, 1972; Carneiro da Cunha \& Viveiros de Castro, 1985; Combes \& Saignes, 1991; Erikson, 1986 (dois destes são franceses unicamente por filiação intelectual).

13. A mãe é praticamente o único parente próximo que sempre escapa às suspeitas. Porém, não se deve imaginar que a vida familiar entre os Jívaro seja persistentemente conflituosa e tomada pela incerteza. Em circunstâncias normais, as relações entre os membros de um grupo doméstico ou local são descontraídas e frequentemente ternas. Ainda assim, ninguém fica surpreso ou particularmente indignado - em oposição a enraivecido - quando membros próximos de uma mesma família se desentendem e se envolvem em uma vendeta. Nesses casos, o grupo se divide e uma ou outra parte se junta a uma unidade territorial diferente.

14. Penso que isso também contribui para explicar a importância de formas de discurso mágico nessa cultura, tais como os anent, feitos para modelar ou modificar os afetos de outros.

15. Os Achuar distinguem e dão nome a uma variedade de doenças. Algumas - geralmente patologias epidêmicas - são rotuladas como "doença de branco"; outras são consideradas "endógenas" e inicialmente se lida com elas recorrendo a plantas medicinais ou a formas domésticas de cura "mágica". Esses males são pensados como "acidentais" apenas no sentido de que o agente responsável por infligi-los pode tê-lo feito não-intencionalmente, mas é claro que a não-intencionalidade dessa intencionalidade imputada é inerentemente suspeita; se uma doença se prolonga ou se agrava, a suspeita rapidamente dá lugar à certeza de um dolo deliberado. Julgamentos acerca do "status da saúde" de indivíduos ou mesmo de comunidades inteiras são, portanto, altamente dependentes da forma percebida das relaçôes sociais: em tempos de conflito iminente ou aberto, não apenas as pessoas tendem a se tornar incomumente propensas a adoecer, como suas doenças, independentemente de seu status taxonômico, são imediatamente atribuídas à agressão xamânica.

16. Isso só é verdade para os homens. As mulheres não procuram sistematicamente o encontro com arutam e o experienciam mais raramente que os homens. A "força" escondida (kakarma-) - antes que a ira - que elas assim adquirem é geralmente descrita em termos de uma vida mais longa e de um maior bem-estar, de relaçóes privilegiadas com as entidades que controlam a fertilidade adequada das plantas de roça, animais domésticos e humanos, e de relaçóes afetivas seguras com os parentes. Vale lembrar também que os encontros femininos com arutam ocorrem nas roças das mulheres, e não na floresta, e que parecem acontecer apenas em tempos de crises emocionais agudas.

\section{Referências bibliográficas}

ALBERT, Bruce. Temps du sang, temps des cendres: représentations de la maladie, système rituel et espace politique chez les Yanomami du sud-est Amazonie brésilienne. Tese, Universidade de Paris, Nanterre, 1985.

ATRAN, Scott. Core domains versus scientific theories: evidence from systematics and Itza-Maya folkbiology. In: HIRSCHFELD, Lawrence. A. \& GELMAN, Susan. A. (orgs.). Mapping the mind: domain specifcity in cognition and culture. Cambridge: Cambridge University Press, 1993.

BELAUNDE, Luisa Elvira. Gender, commensality and community among the Airo Pai of western Amazonas. Tese, Universidade de Londres, 1992.

BLOCH, Maurice. Language, anthropology and cognitive science. Man (N.S.) 26, 183-198, 1991.

.What goes without saying: the conceptualization of Zafimaniry society. In: KUPER, Adam. Conceptualizing society. London \& New York: Routledge, 1992.

Domain specificity, living kinds and symbolism. In: BOYER, Pascal. Cognitive aspects of religious symbolism. Cambridge: Cambridge University Press, 1993.

BOYER, Pascal. Tradition as truth and communication: the cognitive description of traditional discourse. Cambridge: Cambridge University Press, 1990.

. Cognitive aspects of religious symbolism. Cambridge: Cambridge University Press, 1993.

BROWN, Michael F. Tsewa's gift: magic and meaning in an Amazonian society. Washington: Smithsonian Institute, 1985.

CAPISTRANO DE ABREU, João. Grammatica, textos e vocabulario Caxinauas. Rio de Janeiro: Edição de Sociedade Capistrano de Abreu, 1941. 
O CORPO DA ALMA E SEUS ESTADOS: UMA PERSPECTIVA AMAZÔNICA SOBRE A NATUREZA DE SER-SE HUMANO 227

CARNEIRO DA CUNHA, Manuela. \& VIVEIROS DE CASTRO, Eduardo B. Vingança e temporalidade: os Tupinambás. Journal de la Société des Américanistes 71, 191-208, 1985.

CHAUMEIL, Jean-Pierre. Voir, savoir, pouvoir: le chamanisme des Yagua du nord-est péruvien. Paris: Editions de L'École des Hautes Études en Sicences Sociales, 1983.

CLASTRES, Pierre. Chronique des Indiens Guayaki. Paris: Plon, 1972.

COMBES, Isabelle. \& SAIGNES, Thierry. Alter ego: naissance de l'identité chiriguano. Paris: Editions de L'École des Hautes Études en Sicences Sociales, 1991.

DESCOLA, Phillipe. Les lances du crepuscule: relations jivaro. Paris: Plon, 1994.

ERIKSON, Phillipe. Altérité, tatouage et anthropophagie chez les Pano: la belliquese quête du soi. Journal de la Société des Américanistes 72, 185-209, 1986.

GOW, Peter. Of mixed blood: kinship and history in Peruvian Amazonia. Cambridge: Cambridge University Press, 1991.

HARNER, Michael J. The Jivaro: people of the sacred waterfall. New York: Doubleday, Natural History Press, 1972.

KARSTEN, Rafael. Head hunters of the western Amazonas. (Commun. Hum. Lit. 7:1). Helsingfors: Societas Scientiarum Fennica, 1935.

LAWSON, Thomas. E. Cognitive categories, cultural forms and ritual structures. In: Cognitive aspects of religious symbolism. Cambridge: Cambridge University Press, 1993.

LÉVI-STRAUSS, Claude. Du miel aux cendres (Mythologiques 2). Paris: Plon, 1967.

MALINOWSKI, Bronislaw. Os argonautas do Pacifico Ocidental. São Paulo: Editora Abril, 1976.

MCCALLUM, Cecilia. Gender, personhood and social organization amongst the Cashinahua of Western Amazonia. Tese, Universidade de Londres, 1989.
OVERING, Joanna. Images of cannibalism, death and domination in a 'non-violent' society. Journal de la Société des Américanistes, 72, 133-156, 1985.

PELLIZZARRO, Siro M. Nunkui: mitos y ritos. Sucua, Mundo Shuar, Serie Mitologia Shuar, 1978.

. Tsantsa: la celebración de la cabeza reducida. Sucua, Mundo Shuar, Serie Mitologia Shuar, 1980.

PERRIN, Michel. Les praticiens du rêve. Paris: Presses Universitaires de France, 1992.

REICHEL-DOLMATOFF, Gerardo. Amazonian cosmos: the sexual and religious symbolism of the Tukano Indians. Chicago: Chicago University Press, 1971.

SANTOS-GRANERO, Fernando. The power of love: the moral use of knowledge amongst the Amuesha of Central Peru. London: Athlone Press, 1991.

SEVERI, Carlo. La memoria ritual: follia e immagine del Bianco in uma tradizione sciamanica amerindiana. Firenze: La Nuova Italia, 1993.

SPERBER, Dan. The epidemiology of beliefs. In: FRAZER, C (org.). Psychological studies of widespread beliefs. Oxford: Oxford University Press, 1990.

. 1993. The modularity of thought and the epidemiology of representations. In: HIRSCHFELD, L. A. \& GELMAN, S. Mapping the mind in cognition and culture. Cambridge: Cambridge University Press, 1993.

STRATHERN, Marilyn. Parts and wholes: refiguring relationships in a post-plural world. In. KUPER, A. (org.). Conceptualizing society. London \& New York: Routledge, 1992.

TAYLOR, Anne Christine. Remembering to forget: identity, mourning and memory among the Jivaro. Man (N.S.) 28, 653-78, 1993.

. \& CHAU, Ernesto. Jivaroan magical songs. Amerindia (Rev. Ethnoling. Amérind.) 8, 87-127, 1983.

\section{traduzido de}

TAYLOR, Anne-Christine. The Soul's Body and Its States: An Amazonian Perspective of Being Human. The Journal Of The Royal Anthropological Institute. Vol. 2, No. 2 (Jun., 1996), pp. 201-215. 
228 | AnNe-Christine TAYLOR

\section{tradutores Eduardo Soares Nunes}

Doutorando em Antropologia Social / UnB

\section{Roberta Cerri}

Mestranda em Antropologia Social / UnB

Marcela Stockler Coelho de Souza

Mestranda em Antropologia Social / UnB

revisora Marcela Stockler Coelho de Souza

Professora Doutora em Antropologia / UnB

Recebida em 26/08/2012

Aceita para publicação em 01/10/2012 